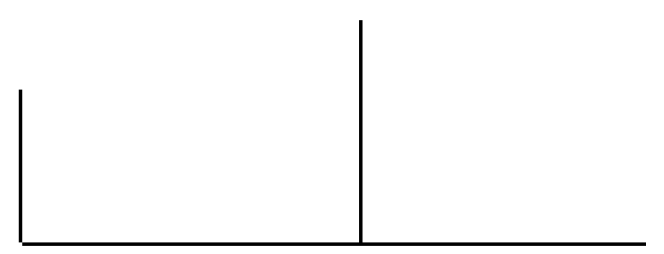

Rev. Latinoam. Psicopat. Fund., IX, 4, 668-675

\title{
Hóspedes e peregrinos Duas montagens subjetivas na psicose*
}

\author{
Adriana Cerdeira \\ Guilherme Gutman
}

\begin{abstract}
Neste trabalho, os autores discutem, no contexto do evento psicopatológico classicamente denominado humor delirante ou trema, dois momentos subjetivos aqui chamados peregrinação $e$ hospedagem. Na acepção proposta para estes termos, ambos estariam delimitados cronologicamente, entre o desencadeamento de um surto psicótico e, no outro extremo, a construção de uma metáfora delirante. A hipótese teórica preliminar é a de que, no trânsito entre a condição de peregrino $e$ a de hóspede, algo de fundamental se passa na perspectiva do psicótico; a hipótese teórico-clínica é a de que o trânsito de uma condição à outra guarda relação íntima com a qualidade e a extensão da rede de laços estabelecida pelo sujeito.
\end{abstract}

Palavras-chave: Psicose, psicanálise, saúde mental, clínica ampliada

* Este texto foi elaborado a partir do trabalho apresentado em mesa-redonda no Simpósio Nacional de Psicanálise e Psicoterapia, realizado na UERJ em setembro de 2005. 
Há algum tempo, estivemos no Aeroporto Internacional Tom Jobim e, enquanto esperávamos a hora do embarque, aproximou-se um homem, aparentemente interessado em nosso cão. Não havia nada de propriamente inesperado nessa aproximação, posto que, pelo fato de nosso cão ser de uma raça peculiar e pouco conhecida, já havíamos nos acostumado a olhares curiosos e a perguntas singelas. Mas havia algo, digamos, ligeiramente estranho em seu aspecto e na forma como ele se inclinou sobre o animal, o afagou e, levantando lentamente os olhos perguntou com muita calma: “ele é manso?”.

Não tinha mais que cinqüenta anos e não menos que quarenta; vestiase como um executivo que tivesse pego emprestado cada peça de roupa que usava: o terno era bem usado, sobrando-lhe um pouco nos ombros e no comprimento, e o conjunto todo, meio amarfanhado, sugeria alguém que tivesse perdido o vôo e, em função disso, tivesse ficado um ou dois dias vagando pelo aeroporto.

Aos poucos, fomos percebendo que o que tinha sido perdido não era apenas um vôo e que o aeroporto vinha sendo o seu pouso há muito mais que dois dias; na verdade, morava nas áreas públicas do Galeão: cadeiras, salas, corredores, setores, escadas, compondo assim um personagem identificado, sobretudo pelos funcionários, como "o maluco do Aeroporto". Havia, portanto, uma identidade, mesmo que atribuída por outros e, de algum modo, uma vida social, ainda que feita essencialmente desses olhares curiosos, perguntas, risinhos e, eventualmente, pequenas ironias. Durante o pouco tempo em que estivemos em contato, aproximaram-se dois taxistas, desses que fazem ponto por lá, pegando e trazendo turistas, e perguntaram coisas como: "Hoje você vai dormir no Terminal 1 ou 2?" ou “Quando é que você vai viajar?”. Ao que o nosso personagem, sem dúvida psicótico, respondia com um olhar manso, de infinita paciência, ou com respostas meio vagas. Num primeiro momento, o que mais chamou a atenção foi o fato de ele ter aparentado indiferença às provocações dos 


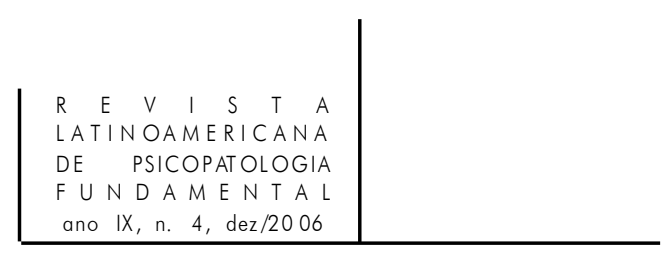

taxistas. Eles, como bons neuróticos, sabiam que o estavam provocando, mas talvez não soubessem explicar por que ele não se sentia provocado, uma vez sabendo que outros neuróticos, taxistas ou não, certamente não ficariam indiferentes a ironias desse tipo.

Pois ele passava meio incólume por aquela sabatina, talvez em parte porque estivesse muito concentrado sobre o seu personagem e suas funções, mas também, porque aquelas provocações não tocavam aquilo que era provavelmente o mais importante para ele: viver plenamente o seu personagem e as funções que supunha endereçadas a ele. Problema para ele, isto sim, seria caso algum funcionário administrativo dissesse que ele não poderia mais circular pelo Aeroporto ou caso fosse removido para alguma instituição psiquiátrica e não conseguisse, por assim dizer, integrar este novo evento à sua construção delirante. Em suma, para ele era suportável, e até relativamente fácil, passar indiferente às intervenções externas que, ao arranharem um certo verniz narcísico, incomodariam a neuróticos; mas uma intervenção que impedisse ou dificultasse o seu trabalho de construção e exercício delirante seria um problema sério, especialmente no caso de lhe pedir um tipo de solução que não estivesse pronto a oferecer.

Naturalmente, estar no Aeroporto, para ele, não era estar em qualquer lugar. Ao contrário, estar lá correspondia, justamente, a estar em algum lugar; em interromper a peregrinação, ainda que temporariamente, e pousar: hospedar-se no Aeroporto por algum tempo. Estranha condição essa da psicose, que pode fazer de alguém identificado socialmente como um andarilho, como um nômade, alguém que encontra hospedagem no local onde tantos partem e chegam e que é confluência de todas as rotas. Aconteceu de nosso personagem encontrar uma hospedagem, ou seja, um local que o tenha acolhido e lhe fornecido um pouso. Mas terá sido apenas coincidência que seu pouso fosse, justamente, um lugar de passagem? Terá sido apenas coincidência que aquilo que aparentemente confere a ele uma amarração é, por outro lado, uma identidade instável, de um viajante, de alguém que está sempre em trânsito? Afinal, era hóspede ou peregrino o nosso personagem? Quanto tempo ele levaria até partir daquela hospedagem e retornar à peregrinação? Quando a intervenção clínica é dispensável ou indispensável?

Neste trabalho queremos discutir as idéias de hospedagem e de peregrinação, entendidas como realidades psíquicas que indicam, respectivamente, o caminho em direção a algum lugar de estabilidade mínima ou o trânsito por circuitos imprecisos. É preciso cuidado para não vincular à idéia de hospedagem a situação dos moradores ou freqüentadores de instituições psiquiátricas e à idéia de peregrinação a situação dos ditos itinerantes que, sem destino específico, vagam pela cidade. Em cada um desses grupos, há pacientes que, por assim dizer, habitam casas e outros que, em contrapartida, permanecem em trânsito. 
As categorias que propomos falam menos da circulação física que fazem nossos personagens e mais de uma posição subjetiva: de que modo se dão suas tentativas de amarração? Há nessas vidas algum ponto de pouso, algum descanso na errância? E se há, qual é? Por este motivo aquilo que vai caracterizar alguém como sendo um hóspede ou um peregrino não é o lugar em que vive, mas os entrecruzamentos de sua rede subjetiva com os seus pontos de vôo e pouso.

A clínica tem revelado que essas trajetórias não são meros acasos, mas antes algum tipo de readaptação à vida. Estaria o hóspede em paz com seu pouso ou apenas desinvestido? Estaria o peregrino em busca do lugar ideal, ou sua busca é pelo trânsito que faz de um ponto a outro? Estamos com isso querendo dizer que, aquilo que talvez importe mais à clínica, seja a idéia da regularidade, a idéia de que aquilo que sustenta o nosso paciente tem a ver com a construção de algo que ligue os pontos de pouso que já teve em sua história. Ocasionalmente, essas construções necessitam de pouca ou nenhuma intervenção de nossa parte, por mais que isso possa contrariar a idéia vigente de que os pacientes estariam necessariamente melhores sob o nosso olhar clínico. Contudo, ainda que menor do que gostaria o nosso furor curandis, o lugar da nossa intervenção é o de buscar esta regularidade, colando, costurando fio por fio com nosso paciente a história que ficou perdida em pousos longínquos.

Antônio era um paciente que morava há cerca de vinte anos no hospital. Pelos corredores, com sua bolsa a tiracolo, pedia a nossa intervenção ao passar perguntando a quem quer que fosse: "tem cartaz, panfleto, cartão telefônico usado?”. Mas ao nos aproximarmos, notamos que ele começava a nos dirigir outros pedidos. Pedia não apenas que lhe déssemos algo, mas sim que “digitássemos no computador" os seus "escritos”. Esse segundo pedido não era como o primeiro, feito a qualquer um, era mais endereçado e, de certa forma, incluía o outro em seu trabalho: "escolhe uma letra bem grande. Faz ficar bem nítido", ele dizia, referindo-se aos cuidados necessários que deveríamos ter com seus escritos. O trabalho era seu, mas a letra e a nitidez eram garantidas por nós. Segundo Antônio, quando via seu trabalho digitado, “a percepção fica mais clara, mais nítida, abre os olhos para a vida e ajuda a esclarecer a minha mente obscura”.

O hospital com seus técnicos e funcionários funcionava para clarear sua mente obscura. Era uma rede: uns guardavam cartões para lhe dar, outros arrancavam os rótulos das embalagens sabendo que o interessariam e alguns digitavam seus escritos. Essa rede de coletores e digitadores funcionava como sustentáculo para o trabalho estabilizador de Antônio. Dos cartões, cartazes e panfletos que recebia coletava as frases que lhe interessavam. Essas frases eram, posteriormente, passadas para o papel formando um novo conjunto, mais um item 


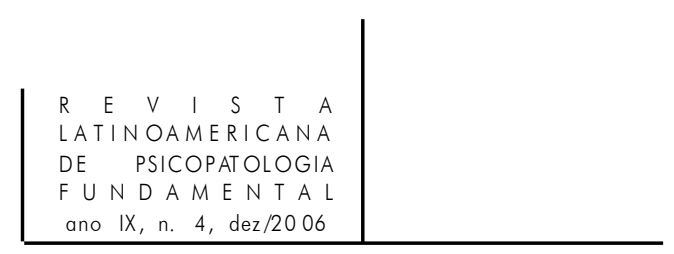

da sua coleção. Mas o trabalho não acabava aí, a arte final ficava a cargo do outro, que ao digitar no papel, ia clareando a mente de Antônio. E assim ele ia, conhecido por todos, ajudado em sua coleta por muitos. Antônio era hóspede.

Que fique mais uma vez claro, que o fato de chamá-lo de hóspede, nada tem a ver com o fato de ser morador do hospital. A hospedagem de Antônio foi conquistada com o trabalho incansável de anos de coleta e reciclagem que garantiram a ele um lugar e uma função. O início dessa coleta coincide com a separação de sua mãe: “desde esse dia eu perdi a visão dela, nunca mais achei ela... o nome dela é Lea... aí começou a vir na minha cabeça - Lea, leia, Lea, leia... e eu comecei a juntar papel, a ler”. Antônio coletava palavras, frases ditas pelos funcionários e pelos pacientes, frases encontradas nos panfletos que colecionava, músicas que ouvia, coisas que pensava e outras que, talvez, alucinasse. "Escrever e ler é o meu mecanismo de defesa”, ele dizia.

Mas antes deste mecanismo de defesa, o que havia era um sujeito alucinado, que andava nu pelo bairro, que vinha trazido pela polícia e que agredia os vizinhos. Essa errância em que se encontrava e que o fazia tão peregrino, sem pouso, foi interrompida com a internação. Mas ele continuava peregrino no hospital, foi preciso encontrar um suporte, os escritos, no caso, para que pudesse circular no mundo sem "ficar louco com fuga de idéias". Assim, os escritos funcionaram como um passaporte para algum estatuto que não lhe era naturalmente acessível, ele dizia: "você tem uma coisa que eu não tenho: eu preciso de base de sustentação para deixar a fala sair”. Parecia-nos surpreendente que Antônio pudesse ser tão preciso para definir a função do trabalho estabilizador que encontrara. E, mesmo que momentaneamente, essa sustentação era o início da hospedagem de Antônio, quando deixava a peregrinação, porque havia encontrado o caminho para ter uma base, de sustentação, como ele dizia.

Antônio queria voltar para casa, pois "hospital é lugar de sofrimento". No entanto sabemos que foi só no hospital que ele pôde experimentar algum continente, algo que o barrasse minimamente. A circulação nos corredores, os digitadores que encontrava foram sendo parte dessa borda que ora se formava e ora desvanecia, mas que, graças à sua busca incansável, o mantiveram mais próximo da superfície. A chave para esse apoio veio alucinatoriamente, foi Lea que virando leia, deu-lhe uma chance de não ser mais um que ouve vozes, mas a de ser um "estudante" dos escritos, capaz de sair da passividade da invasão para a atividade de criar coleções. Mas esse comando - leia! - só pôde ser mais do que uma alucinação porque Antônio encontrou em seu caminho outros que fizeram de seu manuscrito frágil e incapaz de protegê-lo, algo que deixa "mais consciente de si”, porque ao transformar as suas letras soltas e desiguais num conjunto ordenado, conferiam ao seu trabalho o estatuto de barra, estatuto transferido, emprestado de fora, mas que lhe servia. 
Neste trabalho falamos de dois hóspedes: o primeiro fora de circuitos psiquiátricos, fora do que seria propriamente um lugar de acolhimento; o segundo absolutamente atravessado por tais circuitos. Aparentemente em posições opostas - um fora e o outro dentro -, mas ambos remetidos a lugares e pessoas que funcionam como referência, como pouso, o que permitiu a possibilidade de serem mais hóspedes do que peregrinos.

Em resumo, com o que temos até aqui, podemos concluir algumas coisas:

1. Há hóspedes e há peregrinos, tanto fora dos circuitos terapêuticos, como dentro desses circuitos.

2. A clínica da psicose faz muito pelo paciente quando não o atrapalha, quando o auxilia a se hospedar. Na realidade, não se pede aos técnicos mais do que compor com o paciente uma versão possível e sustentável de aeroporto ou de casa.

3. A condição de hóspede ou de peregrino são momentos distintos da errância psicótica, sendo esta entendida como o período anterior ao do encontro de uma metáfora delirante.

4. Um peregrino é um habitante do crepúsculo; daquilo que a tradição psicopatológica denomina "humor delirante" ou "trema" - aquele período anterior ao da constituição de um delírio. Um hóspede, como o peregrino, ainda não encontrou o delírio, mas na condição subjetiva de hospedagem, ao contrário da peregrinação, já é possível notar um trabalho hercúleo na busca da estabilização.

5. O interesse que possa haver no estudo deste momento da errância psicótica - que aqui chamamos de hospedagem - é o de estudar e aprender com os caminhos necessariamente singulares de reconstituição da rede simbólica ou, como no início disse Freud, da construção de um mundo no qual se possa voltar a viver.

\section{Referências}

Calligaris, Contardo. Introdução a uma clínica diferencial das psicoses. Porto Alegre: Artes Médicas, 1989.

Cavalcanti, Maria Tavares. O tear das cinzas. 1992. 356 p. Dissertação (mestrado em Psiquiatria), Instituto de Psiquiatria da Universidade Federal do Rio de Janeiro.

Freud, Sigmund (1924). A perda da realidade na neurose e na psicose. In: Edição Standard Brasileira das Obras Psicológicas Completas. Rio de Janeiro: Imago, 1974. v. XIX. 


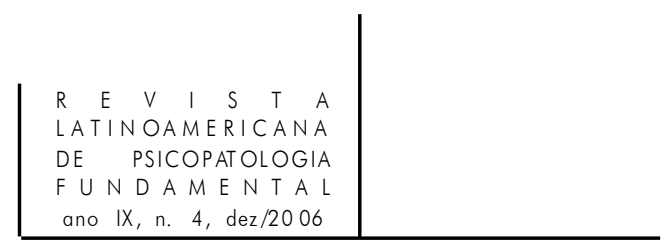

(1911-1913). Notas psicanalíticas sobre um relato autobiográfico de um caso de paranóia (Dementia Paranoides). In: Edição Standard Brasileira das Obras Psicológicas Completas. Rio de Janeiro: Imago, 1969. v. XII.

JAsPers, Karl (1913). Psicopatologia geral. Rio de Janeiro/São Paulo: Atheneu, 1979. v. 1.

LACAN, Jacques (1955-1956). De uma questão preliminar a todo tratamento possível na psicose. In: Escritos. Rio de Janeiro: Jorge Zahar, 1998.

(1955-1956). O seminário. Livro 3. As psicoses. Rio de Janeiro: Jorge Zahar, 2002.

(1957-1958). O seminário. Livro 5. As formações do inconsciente. Rio de Janeiro: Jorge Zahar, 1999.

Souza, Neuza Santos. A psicose - um estudo lacaniano. Rio de Janeiro: Revinter, 1999.

TyKAnori, Roberto. Contratualidade e reabilitação psicossocial. In: PITTA, Ana Maria Fernandes (org.). Reabilitação psicossocial no Brasil. São Paulo: Hucitec, 1996. p. 55-9.

Verztman, Julio e Gutman, Guilherme. A clínica dos espaços coletivos e as psicoses. In: Venancio, Ana Teresa e Cavalcanti, Maria Tavares. Saúde metal - campo, saberes e discursos. Rio de Janeiro: Edições IPUB/CUCA, 2001. p. 39-72.

\section{Resumos}

En este trabajo los autores discuten, en el contexto del evento psicopatológico denominado clásicamente humor delirante o trema, dos momentos subjetivos aquí llamados peregrinación y hospedaje. En la acepción propuesta para estos términos, ambos estarían delimitados cronológicamente, en un extremo, por el desencadenamiento de un brote psicótico y, en el otro, por la construcción de una metáfora delirante. La hipótesis teórica preliminar es la de que en el tránsito entre la condición de peregrino a la de huésped, algo fundamental sucede en la perspectiva del psicótico; la hipótesis teórico-clínica es que el tránsito de una condición a otra guarda relación íntima con la cualidad y la extensión de la red de lazos establecida por el sujeto.

Palabras claves: Psicosis, psicoanálisis, salud mental, nuevos procesos clínicos

Dans le contexte de l'événement psychopatologique habituellement compris comme humeur délirante, les auteurs discutent à propos de deux moments subjectifs ici nommés comme pèlerinage et hébergement. Dans le sens qu'on y propose pour ces deux termes, ils seraient tous les deux délimités chronologiquement d'un côté par le déclenchement de la crise psychotique et, dans l'autre bout du processus, par la 
possibilité de construction d'une métaphore délirante. L'hypothèse théorique préalable de cette recherche consiste à imaginer que, du point de vue du psychotique, il se passe quelque chose de fondamental dans le mouvement qui se fait entre sa condition de pèlerin et celle de hôte. Bref, l'hypotèse théorico-clinique de ce travail consiste à voir dans le mouvement qui mène d'une condition à l'autre un rapport intime avec la qualité et l'extension d'un réseau de liens établi par le sujet.

Mots clés: Psychose, psychanalyse, santé mentale, nouveaux procédés cliniques

This paper presents in the context of the psychopathological event classically called pre delusional state a discussion of two subjective states, named here, respectively, pilgrimage and lodging. These two expressions refer to some period of time between the outburst of a psychotic fit and the creation of a delusional metaphor. The preliminary theoretical hypothesis is that in the passage from the pilgrim condition to the lodger one, something extremely important goes on; the theoretical clinical hypothesis is that the passage from one condition to the other, is closely related to the quality and the extension of the net of of links established by the subject.

Key words: Psychosis, psychoanalysis, mental health, new clinical procedures

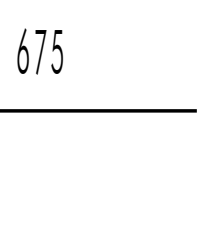

